Article

\title{
Experimental Assessment of a Methodology for the Indirect in-Cylinder Pressure Evaluation in Four-Stroke Internal Combustion Engines
}

\author{
Luca Romani $^{1}$, Alessandro Bianchini ${ }^{1}{ }^{10}$, Giovanni Vichi $^{2}{ }^{(\mathbb{D})}$, Alessandro Bellissima ${ }^{2}$ \\ and Giovanni Ferrara ${ }^{1, *}$ \\ 1 Department of Industrial Engineering (DIEF), Università degli Studi di Firenze, via di Santa Marta 3, \\ 50139 Firenze, Italy; luca.romani@unifi.it (L.R.); alessandro.bianchini@unifi.it (A.B.) \\ 2 Yanmar R\&D Europe, Viale Galileo 3/A, 50125 Firenze, Italy; giovanni_vichi@yanmar.com (G.V.); \\ alessandro_bellissima@yanmar.com (A.B.) \\ * Correspondence: giovanni.ferrara@unifi.it; Tel.: +39-055-275-8777; Fax: +39-055-275-8755
}

Received: 6 July 2018; Accepted: 26 July 2018; Published: 30 July 2018

\begin{abstract}
Recent innovations in engine control and diagnostics are providing room for development of innovative combustion approaches (e.g., low-temperature combustion) able to minimize the creation of pollutants. To ensure the constant fulfillment of the prescribed thermodynamic conditions, however, a fast real-time monitoring of the in-cylinder pressure is needed. To this end, dynamic pressure sensors, flush-mounted on the cylinder head, are commonly used. With this approach, the measurement accuracy is high, but the durability is limited by the harsh working conditions. The installation on the cylinder head is also complex. The development of robust and effective indirect measurement systems could then represent the enabler of a further development of this technology. In the present study, an innovative methodology to measure the in-cylinder pressure has been conceived and extensively tested on a four-stroke single-cylinder engine. The proposed approach is based on the analysis of the mechanical stress on the engine studs by means of a piezoelectric strain washer. This solution allows the user for a rapid and cost-effective sensor installation, described in the paper along with the signal post-processing techniques. Results showed good accuracy and robustness of the methodology, making the results of practical use for engine control.
\end{abstract}

Keywords: strain washer; indirect measurement; in-cylinder pressure; not intrusive; pressure peak; MBF50; knock; misfire

\section{Introduction}

While thermodynamic efficiencies are rapidly reaching their technical limit, increasing attention is paid by researchers and manufacturers in further reducing both pollutant emissions and fuel consumption of internal combustion engines. To this end, a better control and management of the combustion process has become a key factor [1]. For example, low-temperature combustion engines could represent a very promising technology to achieve both a high efficiency and a limitation of pollutants [2]. To do so, they need to work in a narrow area of the combustion space characterized by medium-low equivalence ratios and medium-low combustion temperature in order to ensure low soot and NOx formation. However, the constant fulfillment of strict thermodynamic requirements inside the combustion chamber can be technically challenging [1]. Moreover, the conventional open-loop engine control systems are not able to compensate for manufacturing variations, aging, wear, variation of fuel properties and environmental conditions like pressure, temperature, humidity and so on.

In particular, the in-cylinder pressure is one of the most useful parameters for the evaluation of the combustion quality since, in a closed-loop monitoring system, it allows the determination 
of many parameters related to engine operating conditions such as performance, fuel economy, pollutants and acoustic emissions [3,4]. For example, based on an exact knowledge of the in-cylinder pressure, a control system could actively regulate the spark timing or the injection timing, as well as the exhaust gas recirculation (EGR) and the air-to-fuel ratio (AFR) or the fuel injected quantity in order to have several benefits in terms of performance, fuel economy and emissions over the whole life of the vehicle [5]. Additional benefits achievable with a similar approach could be the detection of misfire, knocking and pre-ignition, the possibility (in a multi-cylinder engine) of operating with the optimal spark timing and injection timing quantity for each cylinder in order to balance the cylinder-to-cylinder variations [6-11]. The possible advantages of a real-time feedback on the in-cylinder pressure are then apparent. To this purpose, an in-cylinder dynamic pressure sensor is commonly used to measure the indicated parameters, especially during detailed test bench analyses of new units. This type of sensors presents however poor long-term reliability due to the harsh environment of the combustion chamber, characterized by high temperature and pressure, combined with the presence of combustion residuals. Reliability issues, combined to the high cost of the sensor, then make them presently not suitable for common use in industrial applications.

Many researchers in recent times focused their attention on developing an indirect in-cylinder pressure estimation technique [12-14], i.e., a system able to avoid any physical access to the combustion chamber. By doing so, the mechanical complexity and cost of the system are reduced, while the long-term reliability is increased [15-17]. On the other hand, a more complex data processing is necessary to correlate the measured quantity to the pressure within the cylinder. In the technical literature, the most diffused solutions are based on the measurement of engine block vibrations [18], the crankshaft speed fluctuations [19] and the acoustic emissions [20], respectively. The main benefits and drawbacks of these technologies are briefly summarized below:

- Acoustic emissions: The acoustic emissions generated during the combustion phase are a good indicator of the combustion phenomena, and therefore they can be used quite easily to reconstruct the pressure trend inside the cylinder [20]. The typical experimental layout consists of a microphone mounted on top of the cylinder block. During the engine operation, unfortunately, a wide range of possible spurious sources as piston slap, valve clatter, gas turbulent flow and many other fluid and mechanical events can generate acoustic emissions that can lead to bias errors in the measurement process: it is then mandatory to develop specific signal processing algorithms to isolate the significant features and remove the events not related to combustion. For example, the complex spectrum analysis (i.e., the one using the complex value of the Fourier Transform [21]) is applied to the acoustic emission signal. The main advantage of the acoustic emissions analysis is that it has a high signal-to-noise ratio in comparison to engine vibration signals, being then particularly suitable for the pressure curve reconstruction, especially on diesel engines. The pressure signal reconstructed from the acoustic emissions is then generally more accurate than that obtained from vibrations [22,23]. On the other hand, data acquisition and analysis require expensive and highly-specialized devices, due to the very high frequency content of acoustic emissions.

- Crankshaft speed fluctuation: During each thermodynamic cycle of the engine, the crankshaft speed changes because of the in-cylinder pressure: when the pressure inside the cylinder increases, the engine torque also increases and this causes a temporary acceleration of the crankshaft. On the other hand, during the compression stroke, the pressure inside the cylinder decrease, causing the crankshaft deceleration. Thus, by measuring with a high acquisition frequency the crankshaft speed (e.g., with a phonic wheel or with an optical encoder) it is possible to trace back the in-cylinder pressure. Between the two measurement techniques, the phonic wheel has the advantage that it is already available in all modern engines [19]. This approach however has some limitations that could be overcome only by an accurate modeling of the vehicle and the engine mechanism [24]. Between these limitations is worth briefly mentioning: (a) the incremental errors due to the construction tolerance and the inaccurate mounting of the cogs [19]; (b) the higher 
the number of cylinders, the lower the speed variations of the crankshaft and then, the lower the applicability of this method; moreover, the higher the engine speed, the lower are the speed variations of the crankshaft because of the engine inertia; (c) the inertia on the entire vehicle and its operating conditions; (d) the torsional deflections, especially at high engine speeds $[25,26]$;

- Force on spark plug: The in-cylinder pressure curve can be obtained also by the measurement of the compression forces acting on the cylinder head structure. The measurement devices can be mounted in various ways [27-30], but the most common location is beneath the spark-plug [31]. This setup requires the modification of the cylinder head, but the output of the strain washers can be easily correlated to the in-cylinder pressure. The main advantage of this arrangement is that the loads on the spark plug caused by the pressure inside the cylinder are greater than those caused by other loads (valve train dynamics, thermal loads, etc.). For these reasons, the post-processing of the data is quite easy. On the other hand, the main drawback of this setup is that the head of the engine has to be modified to house the strain washer. In addition, the spark ignition could cause electrical noises that can affect the accuracy of the in-cylinder pressure measurement.

As one can guess from the above, in the majority of these techniques-and especially in those related to the use of vibrations-the measured quantity can not be directly correlated to the in-cylinder pressure by a linear correlation; the relationship is instead obtained by using different approaches like frequency response functions (FRF), autoregressive moving average techniques (ARMA) or artificial neural networks $(\mathrm{NN})$, which are typically difficult to be implemented within the engine control unit. Moreover, their application is often limited to a narrow operating range of the engine (problems may occur especially at medium-low engine speeds) and a restricted number of engine categories.

Moving from this background, in the present study a methodology for the indirect in-cylinder pressure measurement is presented and discussed. The methodology is based on the use of a piezoelectric strain washer placed on a stud of the engine head. The research activity was carried out by means of three main steps:

- experimental tests on an engine test rig. The signal from a piezoelectric strain washer (SW) and that from a piezoelectric dynamic pressure sensor (PS) were acquired for different engine loads and rotation speeds;

- the signal from the strain washer was post-processed to estimate the in-cylinder pressure with particular focus on the combustion angular range and the main combustion parameters (maximum pressure value, its angular position, and the 50\% mass burned fuel, MBF50, angular position), useful for the close-loop engine control;

- the capabilities of the methodology were finally assessed in both steady-state and transient conditions (considering also non-standard operating conditions) in order to evaluate the reliability on the detection of malfunctioning conditions like knock, pre-ignition and misfire.

This study then represents the proof of concept of a theoretical and technical approach that has a great potential for engine mass production applications thanks to its simplicity and accuracy.

\section{Proposed Approach}

From a theoretical point of view, the pressure acts on the combustion chamber surface and generates a force that is elastically transferred through the cylinder head to the head bolts or studs (see Figure 1). Therefore, by measuring this force (e.g., by a strain washer), one can obtain a direct monitoring of the variations of the combustion chamber pressure. The main advantages of this approach are the intrinsic simplicity and the low computational resources needed to correlate the strength on the head stud and the in-cylinder pressure.

A preliminary study on the application of the strain washer for an indirect estimation of the in-cylinder pressure has been already carried out by some of the authors on a 2-stroke engine [31-33]. In that case, the correlation between the strain washer voltage and the pressure was obtained by using artificial neural networks. 
The major improvement proposed in this study is the proposal of a simplified data processing method based on a linear correlation between the measured force and the in-cylinder pressure.

First, it is worth noticing that the engine stud is characterized by a preload that avoids the disassembling of the coupling between the head and the cylinder block during the engine operation. This solution allows one to consider in first approximation the system (head and cylinder block) as a rigid body. While the head and the cylinder block are highly rigid, the engine studs, according to the general rigidity of the system, are designed slender in order to guarantee a constant preload by varying the operating condition [25]. On this basis, the main assumption proposed here (and validated by means of experiments) is that even during the dynamic operation of the engine the relationship between the in-cylinder pressure $P_{c y l}$ and the measured signal (e.g., the stud strength) can be described as a first order equation (Equation 1), where $\mathrm{k}$ and $\mathrm{q}$ are two calibrating constants; in doing so, the dissipative effects due to engine structure and the thermal deformation are neglected in first approximation.

$$
\text { stud stenght }=k \cdot P_{c y l}+q,[b a r]
$$

Thanks to its simplicity and low cost, this approach is thought to be suitable for on-board engine control systems, without any evident limitation related to the engine operating conditions.

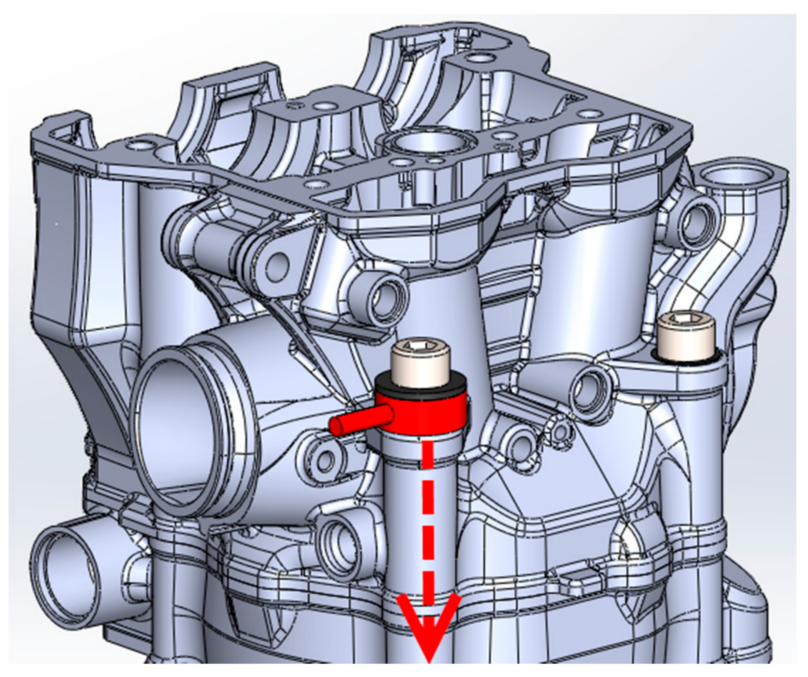

Figure 1. Stress on the engine head screw (illustrative scheme).

\section{Methods and Experiments}

The proposed methodology has been assessed experimentally by means of a gasoline single-cylinder, 4-stroke turbocharged engine for a motorsport application i.e., the Formula SAE competition. To fulfill the requirements of the competition, the engine also had a $20 \mathrm{~mm}$ orifice restriction at the intake. The engine was equipped with double camshaft on the engine head; the main features are reported in Table 1. Based on the engine characteristics, the effective operating range is shifted to pretty-high revolution speeds, being the maximum power obtained at approximately $8000 \mathrm{rpm}$. For the sake of this analysis, the analyzed revolution speeds were comprehended between $3000 \mathrm{rpm}$ and $6000 \mathrm{rpm}$. Lower regimes were deemed not representative of the engine behavior, while higher ones were indeed achievable, but were not considered in this phase of the research for safety reasons at the test bench. 
Table 1. Engine main features.

\begin{tabular}{cc}
\hline Engine type & Gasoline PFI turbocharged \\
Strokes for cycle & 4 \\
Number of cylinders & 1 \\
Displaced volume & $520 \mathrm{cc}$ \\
Stroke & $63.4 \mathrm{~mm}$ \\
Bore & $101.98 \mathrm{~mm}$ \\
Compression ratio & $9.02: 1$ \\
Number of valves & 4 \\
Turbocharger & Single-stage turbine with WG \\
\hline
\end{tabular}

The mechanical stress was measured on one of the four head screws (i.e., the most accessible one, since two out of four screws were oil immersed, while the third was not accessible, needing mechanical modifications of the engine head) by means of a strain washer, whose main features are reported in Table 2. Figure 2 shows the strain washer installation between the screw head and the engine head. The strain washer chosen for the tests had a circular shape, with an internal hole of $10.5 \mathrm{~mm}$ diameter, an external diameter of $22 \mathrm{~mm}$ and a height of $10 \mathrm{~mm}$. The strain washer was of piezoelectric type, therefore the dynamic measurement of the SW (relative sensor) did not depend on the applied preload. The sensor was installed under the left head screw on the intake side: this was indeed the only feasible solution on this type of engine without machining the head (Figure 2). In fact, two head screws were located under the intake and exhaust camshafts, respectively, with relevant issues for the sensor operation, including high lubricant oil temperature, very narrow space for sensor installation and the need for realizing a dedicated path for the sensor cable. The last screw available was the left one on the exhaust side. It was indeed outside the engine head, but there was no space between the screw and the head surface for the installation of the sensor, needing an additional machining. To overcome this issue, since the sensor thickness was $10 \mathrm{~mm}$, a new engine screw-10 $\mathrm{mm}$ longer respect to the original one-was designed and realized in order to properly assembly the engine head. In order to guarantee the same rigidity, all the screws have been lengthened by $10 \mathrm{~mm}$ and a spacer of $10 \mathrm{~mm}$ was installed between each screw and the head. This modification changed slightly the coupling force between the head and the cylinder but it did not affect the correct functioning of the engine. In further detail, the in-cylinder pressure was acquired first with the dynamic pressure sensor and the unmodified configuration; then, the acquisition was repeated with the SW and the new screws, noticing no modification of the engine behavior.

Table 2. Strain washer main features.

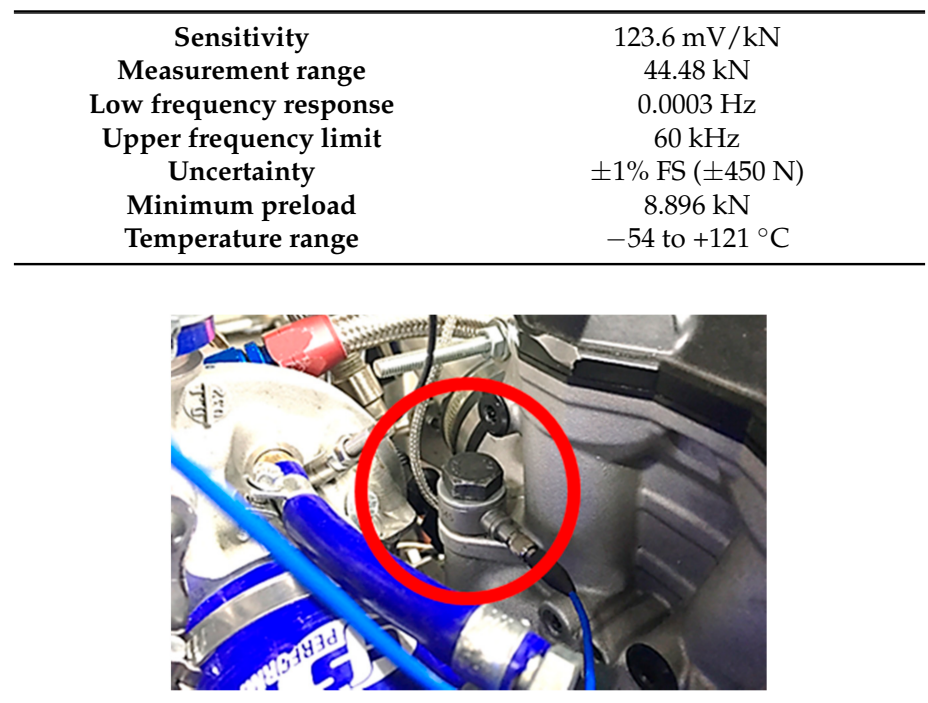

Figure 2. Strain washer installation on engine head. 
For the correct functioning, the engine screws must be screwed with a tightening torque of $55 \mathrm{Nm}$, which corresponds to a preload $(P)$ of $36 \mathrm{kN}$. Since the measurement range $(\mathrm{Mr})$ of the sensor was $44.48 \mathrm{kN}$ the remaining dynamic rage $(D r)$ for the measurement was:

$$
D r=M r-P \cong 8.48,[b a r]
$$

The goal of the activity was to find a proper correlation able to link the SW to the PS signal. The data analysis was carried out on a set of experimental tests performed at the test bench of the Dept. of Industrial Engineering of the Università degli Studi di Firenze [34], varying the engine speed (from 3000 to $6000 \mathrm{rpm}$ ) and the load (from low load to full load), in order to get a representative overview of the whole engine operating range.

\section{Strain Washer Data Analysis}

Figure 3 shows an example of the signal acquired by the strain washer. It can be noticed that the signal of the SW is slightly affected by noise. The noise is produced by the electronic coupling of the SW with the acquisition system. Based on a first numerical estimation, the maximum force acting on a single screw when the pressure is $80 \mathrm{bar}$ (max in-cylinder pressure) is about $2.5 \mathrm{kN}$, so the remaining dynamic range was enough for the tests. The benchmark in-cylinder pressure was measured by a piezoelectric dynamic sensor, whose main features are reported in Table 3.

Table 3. Main features of the in-cylinder pressure sensor.

\begin{tabular}{cc}
\hline Sensitivity $\left(\mathrm{T} 250^{\circ} \mathrm{C}\right)$ & $16.1 \mathrm{pC} / \mathrm{bar}$ \\
Measurement range & $150 \mathrm{bar}$ \\
Uncertainty & $\pm 0.13 \% \mathrm{FSO}$ \\
Diameter & $5 \mathrm{~mm}$ \\
\hline
\end{tabular}

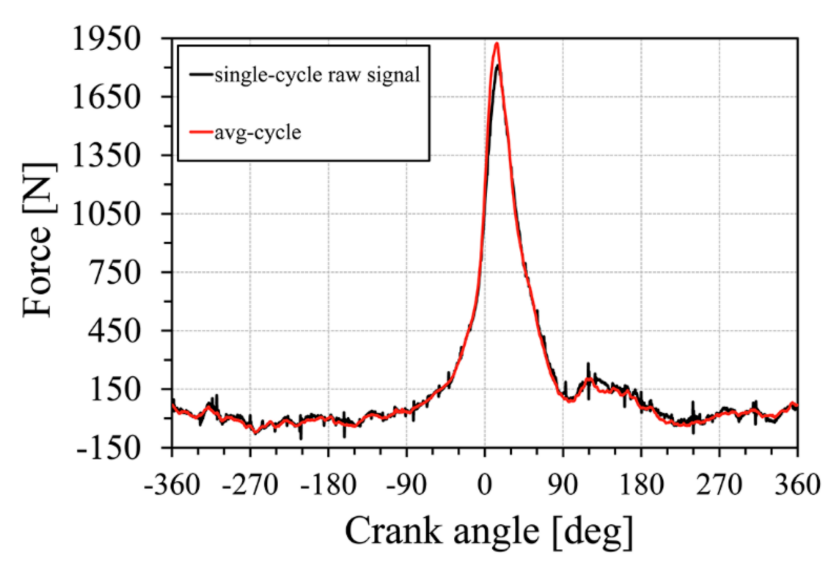

Figure 3. Strain washer signal at $4000 \mathrm{rpm}$ and full load. Single-cycle raw signal vs Average-cycle. The trend differences are due to the cycle-to-cycle variation.

The undesired background noise was sufficiently low and only affected the low-pressure area (intake and exhaust phases) of the thermodynamic cycle. Moreover, the average cycle, based on 100 consecutive cycles, resulted in a smoother trend without significant fluctuations. Nevertheless, in order to properly reconstruct the in-cylinder pressure from the strength signal, a frequency analysis of both PS and SW signals was performed. By considering the average cycle, the Fast Fourier Transformation (FFT) spectrum of the PS signal at different engine operating conditions is represented in Figure 4. The main frequency of the PS signal is the combustion frequency which is directly related to the engine speed, consequently the magnitude of the spectrum is represented in function of the orders (expressed as multiples of the firing frequency). Upon examination of the results, it became apparent that over the 35th order (e.g., $1750 \mathrm{~Hz}$ at $6000 \mathrm{rpm}$ ) the amplitude of the PS 
spectrum was lower than $1 \%$ with respect to the amplitude of the firing frequency in the whole engine operating range.

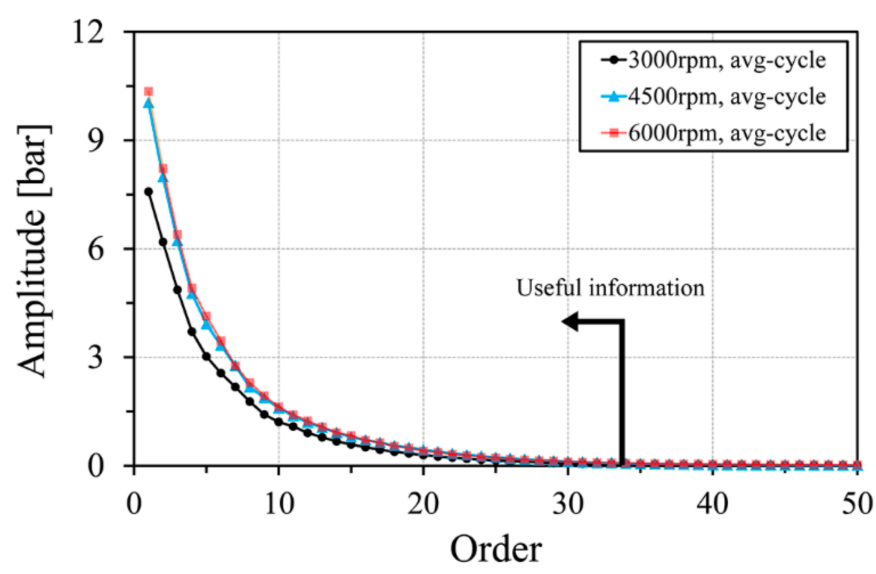

Figure 4. FFT spectrum of the pressure sensor signal at full load and different engine speeds.

Consequently, the useful spectrum content for the in-cylinder pressure analysis is assumed to lie under this order. Same considerations can be done considering the FFT analysis for different cycles at the same engine operating condition (Figure 5): the spectrum shows differences in the low-frequency area due to the cycle to cycle variation but over the 35th order, the amplitude goes almost to zero.

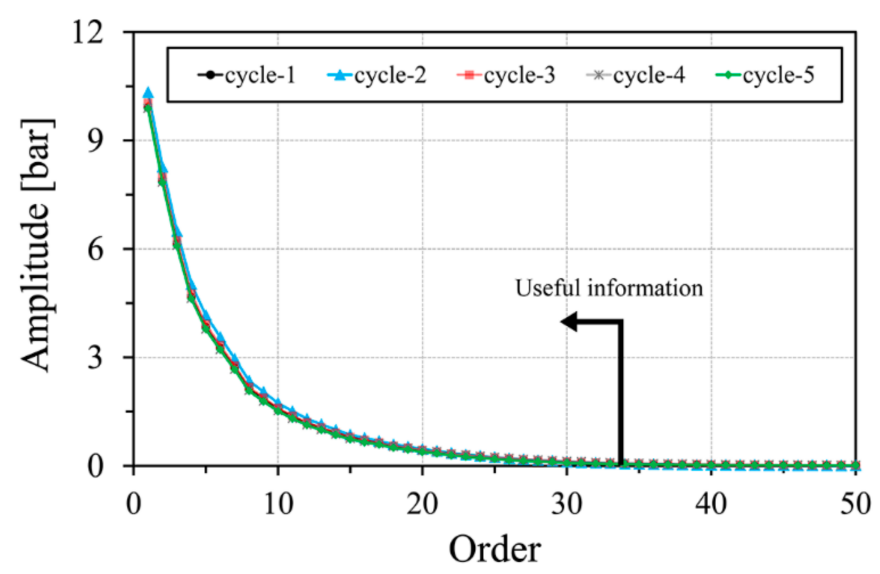

Figure 5. FFT spectrum of the pressure sensor signal of different cycles at the same operating condition (4500 rpm at full load).

According to the above, only the frequency content under the 35th order was taken into account also for the SW signal. The validity of this assumption can be readily noticed upon examination of Figure 6, which depicts the FFT of the SW signal for different engine speed at full load. Moreover, Figure 7 shows in light blue the reconstructed SW signal for a single engine cycle at $4000 \mathrm{rpm}$ and full load, obtained by an inverse FFT of the original signal considering the first 35 orders: it is apparent that no relevant information was lost on the signal, with the only exception of the high-frequency background noise. 


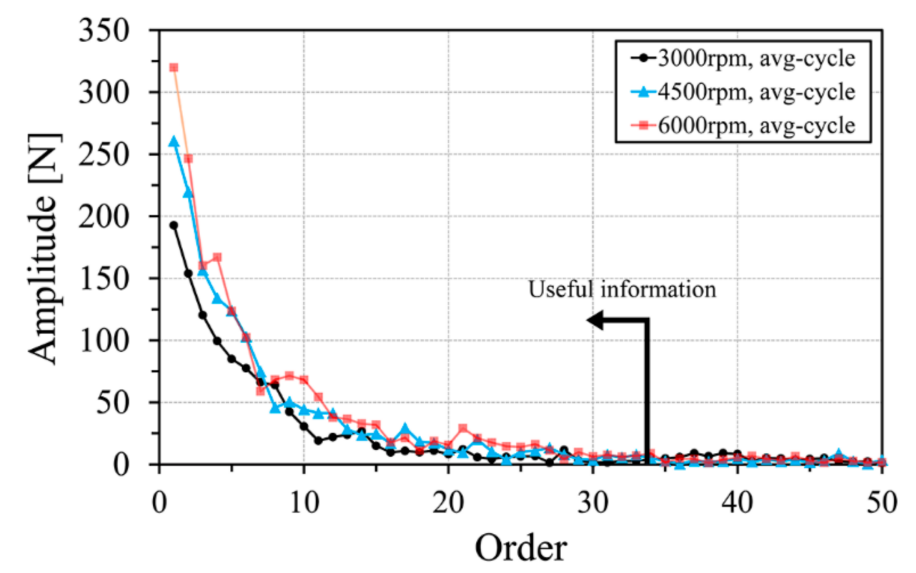

Figure 6. FFT spectrum of the strain washer signal at full load and different engine speeds.

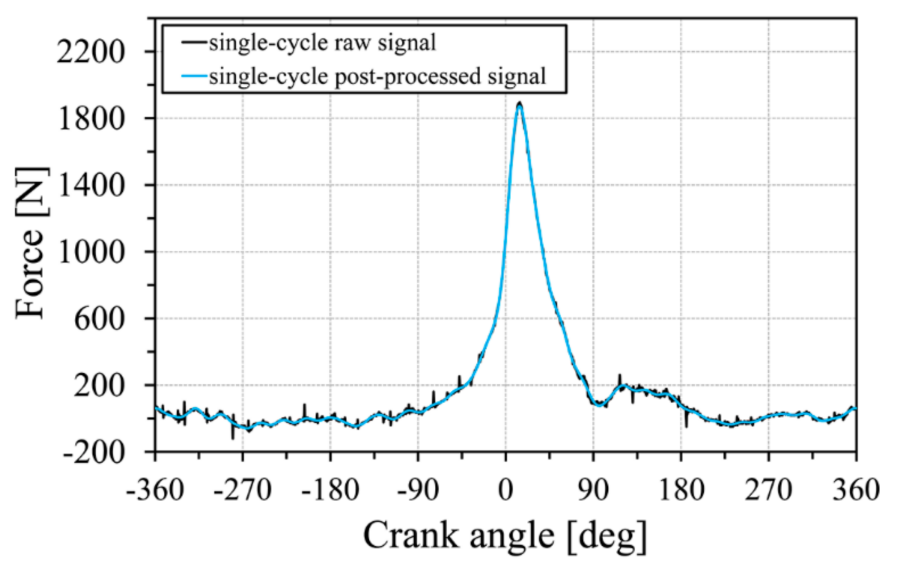

Figure 7. SW signal at $4000 \mathrm{rpm}$ and full load. Single-cycle raw signal vs. Single-cycle post-processed signal.

Stated the above, Figure 8 compares directly the SW signal (N) and PS signal (bar) averaged on 100 consecutive cycles. The figure also displays: (a) the uncertainty of the strain washer; (b) the relative difference between the in-cylinder pressure measured with the PS and that derived from the SW; (c) IVO (Intake Valve Open), IVC (Intake Valve Close), EVO (Exhaust Valve Open), EVC (Exhaust Valve Close) points. In the figure, the SW signal is also graphically scaled in order to match the PS signal at the maximum pressure. It is apparent that the two signals are very similar in the angular region from $45^{\circ}$ Before Top Death Center (BTDC) to $75^{\circ}$ After Top Death Center (ATDC) and in the combustion area, while they differ considerably in the remaining area of the cycle. The reason of this discrepancy may be that the force measured by the SW during the intake and discharge phases is under the uncertainty of the sensor ( $1 \%$ of full-scale), which was equal to $\pm 450 \mathrm{~N}$. Nevertheless, the combustion phase is the main region of interest for the engine management, therefore the following analysis was carried out with special focus on this portion of the cycle. 


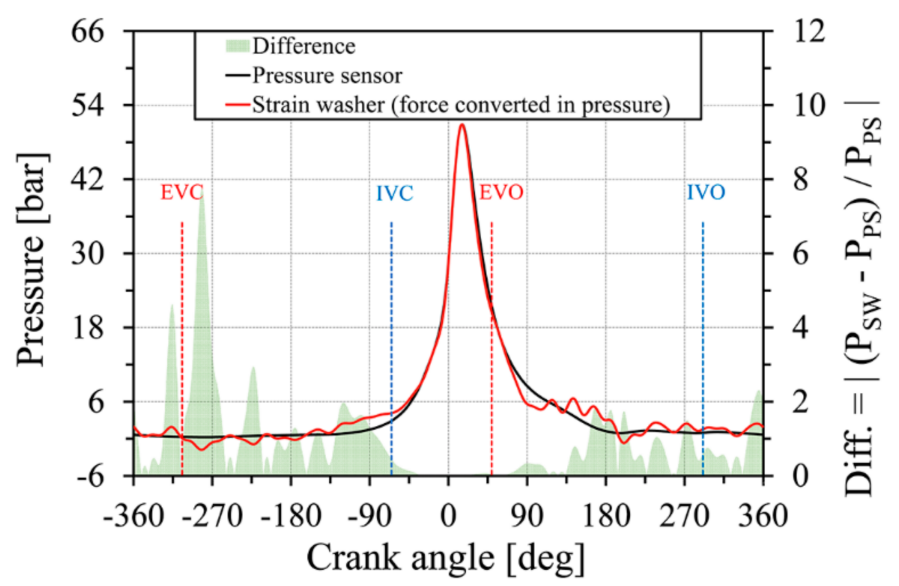

Figure 8. Strain washer signal vs. Pressure sensor signal at $4000 \mathrm{rpm}$ and full load.

Figure 8 also reports in green-shadowed areas the absolute relative difference in terms of pressure between the in-cylinder pressure measured directly with the PS and indirectly derived from the SW signal. From a perusal of the figure, one can readily notice that in the area of interest for the combustion analysis, the difference between the two signal is almost null; on the other hand, the difference during suction and discharge phases is not negligible.

As discussed, this behavior could be related to the higher uncertainty of the strain washer in that regions. However, the agreement found around the crank angles involving the combustion phase corroborates the suitability of the present method for implementation in real-time combustion analyses and control logics. In this view, to further assess the capabilities of the method, it is of interest to understand if this indirect methodology can be adopted to detect the arise of anomalous engine behaviors like knock, misfire or pre-ignition (see Section 4).

Finally, in order to correlate the mechanical stress on an engine stud ( $S W$ signal) with the in-cylinder pressure, the linear correlation reported by Equation (3) was here considered:

$$
\text { in }- \text { cylinder pressure }=\frac{S W}{k}-q,[b a r]
$$

The values $k$ and $q$ (equal to 27.4 and 125.8, respectively, for the present test case) were calculated by considering two angular positions around the firing top dead center (between $-5^{\circ}-+10^{\circ} \mathrm{Crank}$ Angle (CA) around the Firing Top Death Center (FTDC)) where the strain washer signal is considered highly reliable. More in detail, since both the SW and the PS are relative sensors, to accurately calculate $\mathrm{k}$ and $\mathrm{q}$ parameters, it is necessary to set in the right way the absolute value of strength and pressure for both the SW and PS sensors during the measurement. Regarding the PS, the conventional assumption is that the average in-cylinder pressure in a window of $\pm 5^{\circ} \mathrm{CA}$ around the Before Death Center (BDC) with the inlet valve open is equal to the intake pressure that is about 1 bar [35]. In the same angular window, it is assumed that the average strength on the stud measured by the $\mathrm{SW}$ is equal to $0 \mathrm{~N}$, this means that the mechanical apparatus, excluding the preload, is not stressed. Even for turbocharged engines, the strength at BDC can be considered negligible although the in-cylinder pressure at the BDC with the inlet valve opened can be higher than the ambient pressure.

The $k$ and $q$ values, in theory, are constant independently from the engine operating conditions and the choice of the two angular positions around the FTDC since the SW and the PS have a linear behavior. Actually, a dedicated sensitivity analysis purposefully carried out on the choice of these parameters highlighted that there are minimal variations (with maximum difference of about $5 \%$ ) between $k$ and $q$ values calculated at different engine operating conditions; this is mainly due to the strong not-stationary nature of SW and PS measurements and to the uncertainty in the definition of the absolute value of both sensors. Therefore, once the $k$ and $q$ values are evaluated on different engine 
operating conditions, average values of $k$ and $q$ are considered to convert the strain washer signal in pressure during the experimental tests.

\section{Model Capabilities}

The following sensitivity analyses will show the capabilities of the strain-washer-based methodology to properly capture the most important indicators of the in-cylinder pressure and the combustion behavior in a wide engine operating range. The tests were carried out for low $(\sim 10 \div 30 \%)$, medium $(\sim 30 \div 70 \%)$ and high $(\sim 70 \div 100 \%)$ engine load and the full engine operating range (from 3000 to $6000 \mathrm{rpm})$.

\subsection{Detection of the Main Combustion Parameters}

A comparison between the capabilities of the PS and the SW to detect the in-cylinder maximum pressure and its angular position is first presented in Figure 9. Upon examination of the figure, it is apparent that the majority of the measured points lies in proximity of the bisector line, confirming the validity of the proposed linear correlation; the agreement between direct and indirect measurements is good, confirmed by a maximum uncertainty of $\pm 10 \%$ at low load.

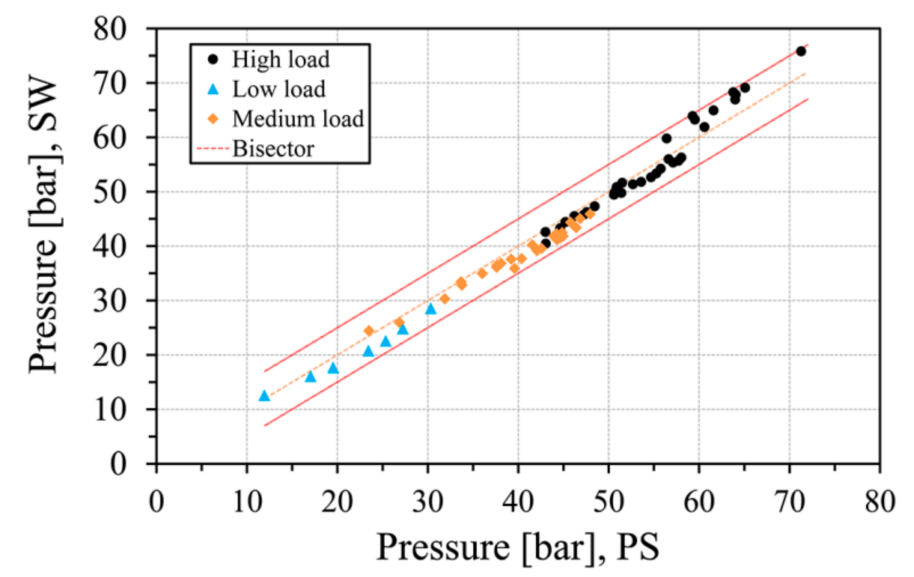

Figure 9. Maximum in-cylinder pressure evaluated by the strain washer and the pressure sensor at different operating conditions in terms of load and regime (from 3000 to $6000 \mathrm{rpm}$ ) on the average-cycle.

In addition to the value of the peak of pressure, the position of the peak in as a function of the crack angle was also investigated. Figure 10 shows the position of the peak evaluated by the strain washer and in-cylinder pressure. All measured points with the only exception of few data at low-load conditions (reported as light-colored diamonds) were included in the range of $\pm 0.5 \mathrm{CA}$ degrees, which indeed represents the error band of the optical encoder. It is worth remarking that the less accurate points measured with the strain washer were recorded for the lowest engine load, which causes mechanical stresses on the load cell near to the uncertainty of the sensor (about $450 \mathrm{~N}$, see Figure 8). Additional confidence on the robustness of the results can be obtained upon examination of Figures 11 and 12, which show the maximum pressure value and its position, respectively, evaluated by the strain washer and the in-cylinder pressure sensor for each of the 100 cycles used to obtain the average one. For the sake of brevity, only the condition of full load at $4500 \mathrm{rpm}$ is depicted, but consistent results were obtained in the other operating conditions tested. As one may notice, the position and the amplitude of the pressure peak indirectly evaluated by the strain washer are approximately the same of the one measured by the in-cylinder pressure sensor also if the single cycle is considered. 


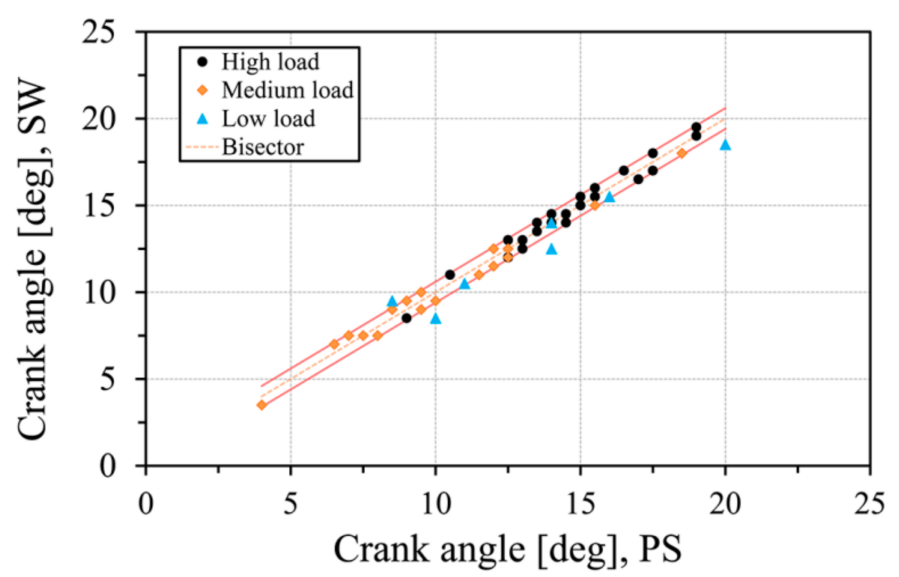

Figure 10. Angular position of the maximum in-cylinder pressure evaluated by the strain washer and the pressure sensor at different operating conditions in terms of load and regime (from 3000 to $6000 \mathrm{rpm}$ ) on the average-cycle.

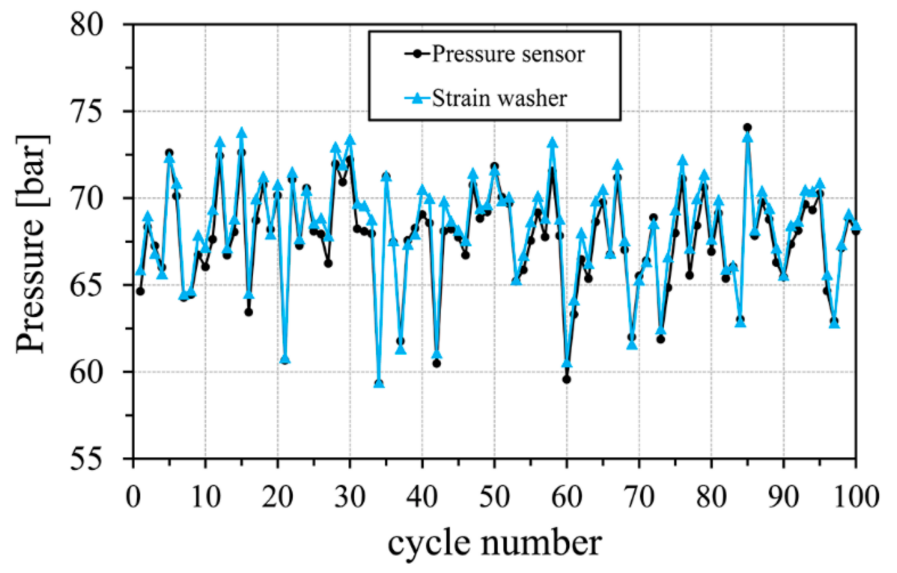

Figure 11. Maximum in-cylinder pressure evaluated by the pressure sensor and the strain washer at $4500 \mathrm{rpm}$ and full throttle on 100 consecutive cycles.

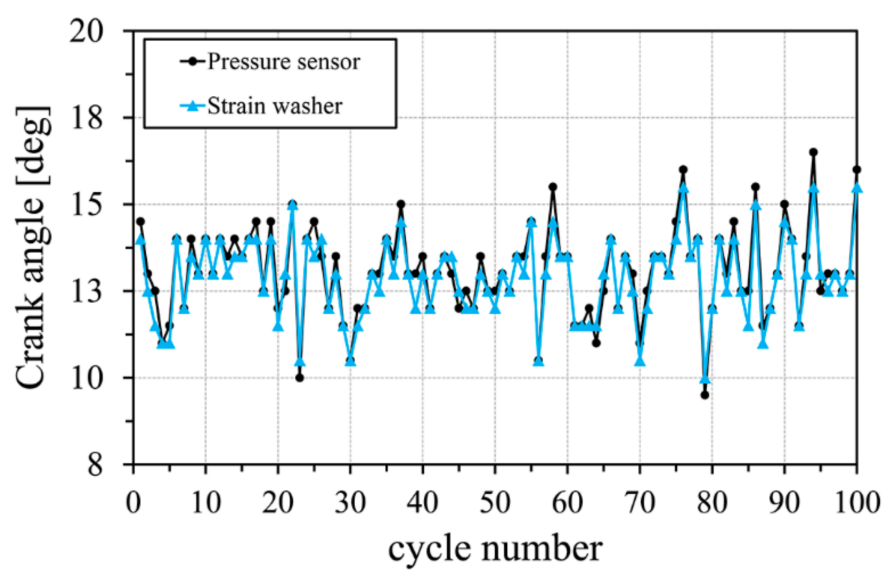

Figure 12. Angular position of the maximum in-cylinder pressure evaluated by the pressure sensor and the strain washer at $4500 \mathrm{rpm}$ and full throttle on 100 consecutive cycles.

This also means that the linear correlation between the pressure measured by the in-cylinder sensor and the mechanical stress on the stud is proved throughout the engine operating range. 
Figure 13 reports the error dispersion on the maximum in-cylinder pressure and its angular position of a single cycle considering 200 consecutive cycles; the right column refers to the pressure peak angular position while the left one to the maximum pressure value. Results confirmed the suitability of the strain washer in predicting the position of the peak. Sensible angular differences between the SW and the PS are limited to only few cases from 4000 to $6000 \mathrm{rpm}$, while at $3000 \mathrm{rpm}$ the difference is more evident but always limited to $\pm 3^{\circ}$ for most of the cases. Data collected at very low load ( $20 \%$ load) as attended appeared slightly more dispersed at all the revolution speeds. The indirect measurement of the max pressure peak showed a difference of about \pm 5 bar in most of the cases, again with a greater dispersion at $3000 \mathrm{rpm}$. The error dispersion appeared independent on the engine load, with the only exception of the case at $3000 \mathrm{rpm}$, where at full load an overestimation of both the max pressure value and the peak position was noticed. An opposite trend was highlighted at $3000 \mathrm{rpm}$ and $50 \%$ load, where there is an underestimation of both the max pressure value and the peak position. This evidence is presently under investigation in order to understand in depth the behavior of the SW at low engine speed.
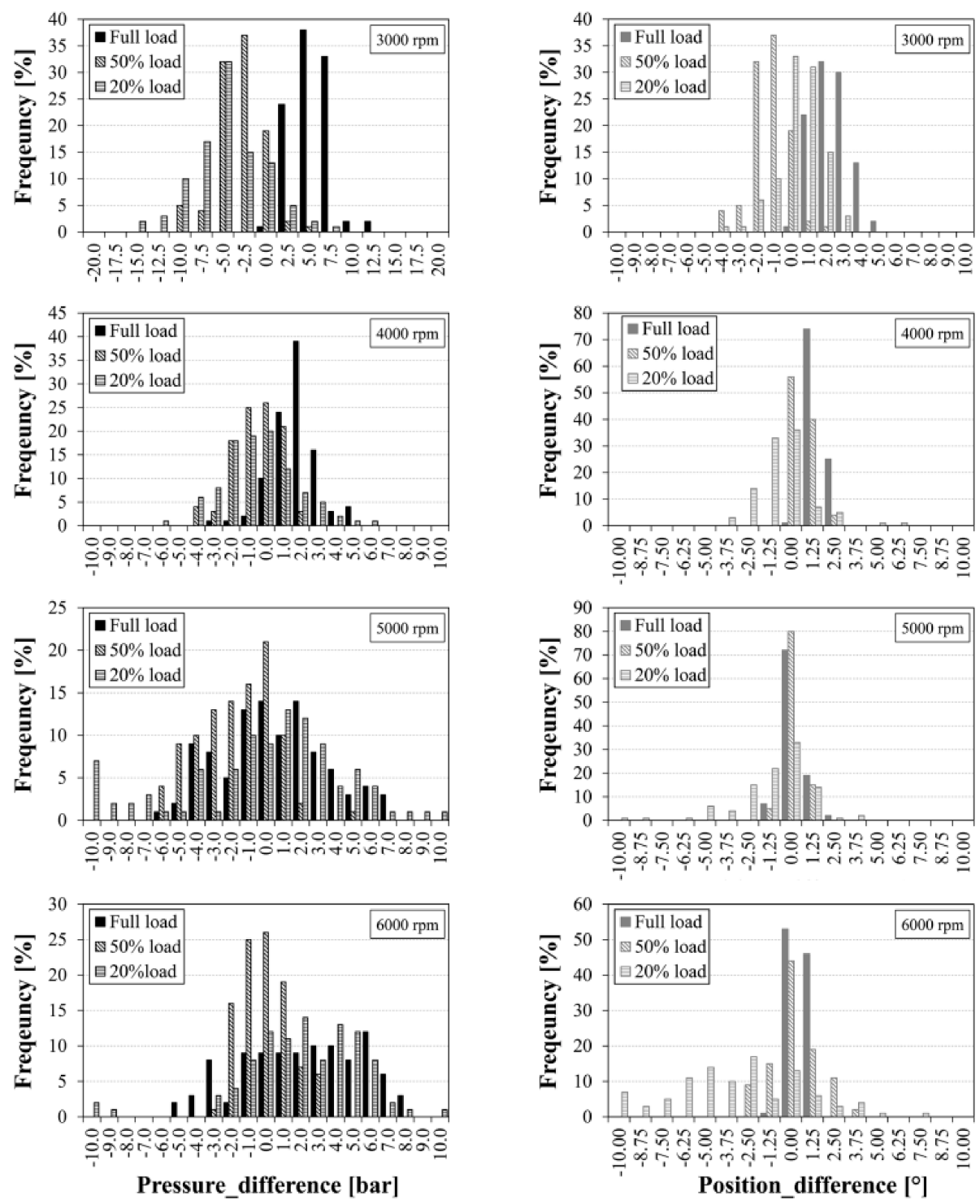

Figure 13. Error on the evaluation of the maximum in-cylinder pressure (left) and its angular position (right) considering 200 consecutive cycles for each graph. Engine speed from 3000 to $6000 \mathrm{rpm}$ at 20\%, $50 \%$ and $100 \%$ of the maximum load. 
Another very important issue in the analysis of the combustion process is represented by the analysis of the mass fraction of burned fuel. The heat release analysis (Equations (4) and (5), please refer to the Nomenclature for a complete list of symbols) was performed by using constant polytrophic coefficient (typically imposed equal to 1.32 for PFI gasoline engine) and by neglecting the heat transfer and crevice terms $[35,36]$.

$$
\begin{aligned}
& \frac{\partial Q_{b}}{\partial \theta}=\frac{\gamma}{\gamma-1} \cdot p \cdot \frac{\partial V}{\partial \theta}+\frac{1}{\gamma-1} \cdot V \cdot \frac{\partial p}{\partial \theta} \\
& Q_{b}=\int_{\theta_{i}}^{\theta_{f}} \frac{\partial Q_{b}}{\partial \theta} d \theta \Rightarrow x_{b}=\frac{1}{Q_{b}} \frac{\partial Q_{b}}{\partial \theta}
\end{aligned}
$$

The S-curve and the main associated parameter for the real time combustion analysis (i.e., MBF50) were evaluated from the SW signal and compared with the one calculated from the PS signal. The MBF50 points evaluated by the SW were found to be fully coherent with the MBF50 calculated with the in-cylinder pressure sensor. The measured error (Figure 14) was always less than \pm 1.5 CA degrees. According to previous analyses, the agreement was good also if the single cycles were considered, as confirmed by Figure 15, which shows the MBF50 position evaluated by the SW and the PS for 100 consecutive cycles at $4500 \mathrm{rpm}$ and full load.

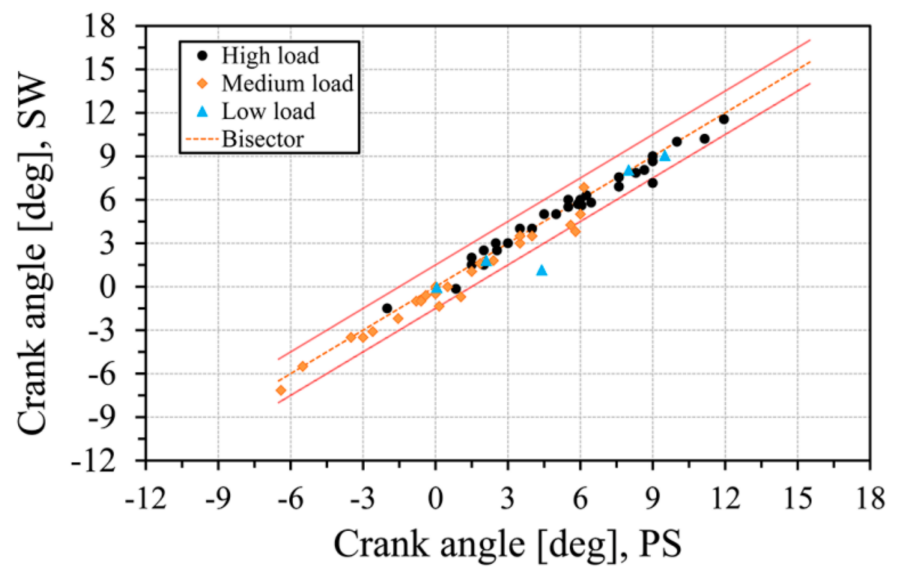

Figure 14. MBF50 evaluated by the strain washer and the pressure sensor at different operating conditions in terms of load and regime (from 3000 to $6000 \mathrm{rpm}$ ) on the average-cycle.

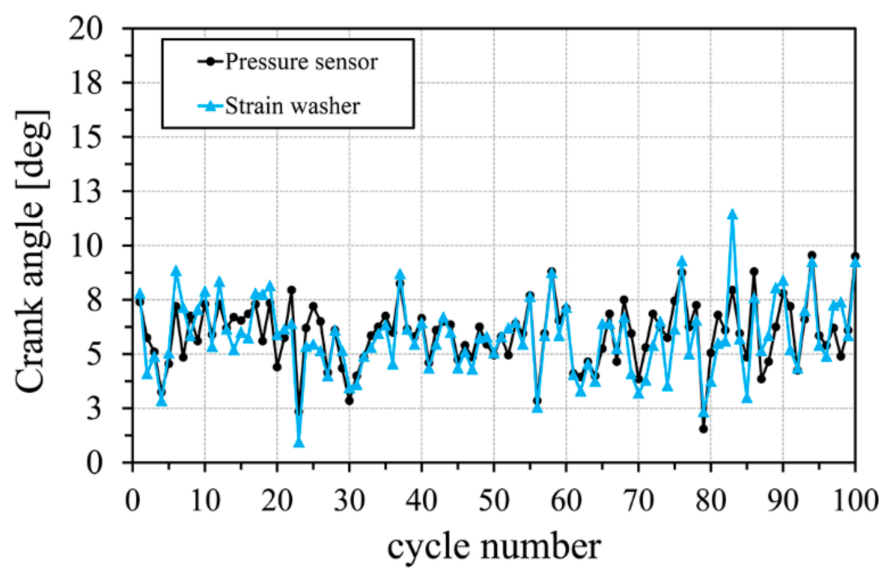

Figure 15. MBF50 evaluated by the pressure sensor and the strain washer at $4500 \mathrm{rpm}$ and full throttle on 100 consecutive cycles.

The response of the strain washer with respect to the pressure sensor was also investigated by considering variations of both air-to-fuel ratio (AFR) and ignition timing advance (IA). The indirect 
measurements (note reported here for brevity) in fact predicted properly both AFR and IA variations. Finally, the accuracy and promptness of the SW was investigated in transient conditions: the results shown in Figure 16 andFigure 17 were carried out at $4000 \mathrm{rpm}$ and full load; in Figure 16, the IA has been increased by $20 \mathrm{CA}$ deg, while in Figure 17 it has been reduced by 5 CA deg. The potentiality of the system in appreciating instantaneous variations is apparent, corroborating the prospects of using this system in the future within innovative real-time control systems for engine management.

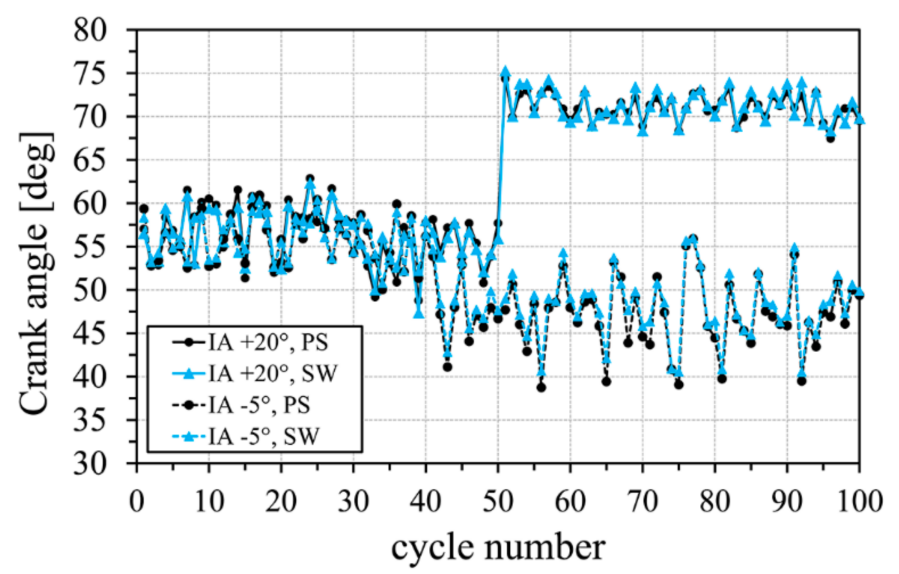

Figure 16. Maximum in-cylinder pressure on 100 consecutive cycles evaluated by the pressure sensor and the strain washer by increasing the ignition advance of $20 \mathrm{CA}$ deg (dashed line) and reducing it of 5 CA deg (solid line) at $4000 \mathrm{rpm}$ and full load.

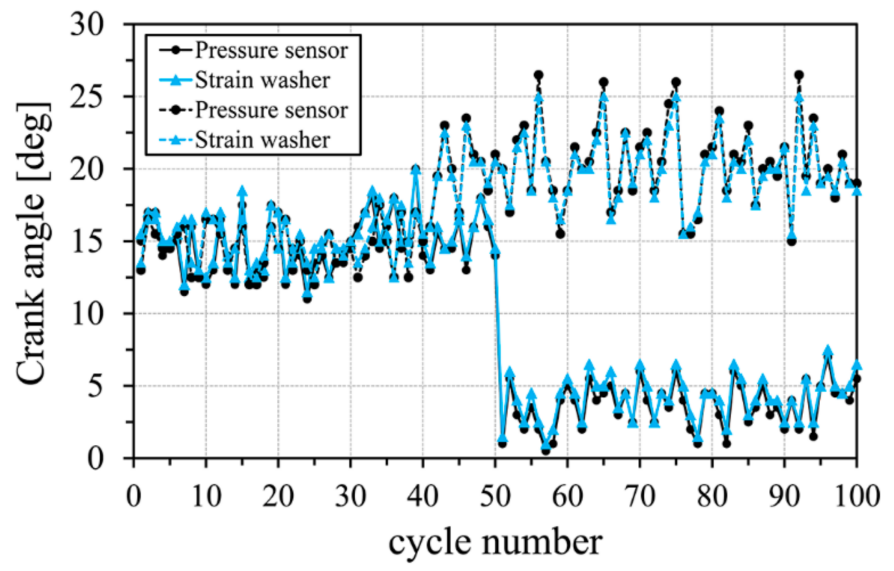

Figure 17. Angular position of the maximum in-cylinder pressure on 100 consecutive cycles evaluated by the pressure sensor and the strain washer by increasing the ignition advance of $20 \mathrm{CA}$ deg (dashed line) and reducing it of 5 CA deg (solid line) at $4000 \mathrm{rpm}$ and full load.

\subsection{Misfiring}

Misfiring can affect the engine functionality, so its prompt detection is extremely important to ensure the correct operation of the engine, since it can operate only a few cycles in similar conditions. To obtain misfiring conditions during the tests, the ignition advance has been reduced instantaneously to a value such as to prevent the ignition of the mixture. Figure 18 shows two normal cycles and two consecutive misfiring cycles. The prediction of the cycles by the strain washer was very good compared with the in-cylinder pressure sensor, and the strain washer worked perfectly also in transient state. The occurring of misfiring could be easily detected by the SW in a working engine by the strong reduction of the maximum pressure; Figure 19a, displays the transient variation of this parameter in case of about 10 misfires in 100 cycles; it is apparent that the estimation of the pressure peak value was 
consistent. Even the trend of the MBF50 position is coherent with the one evaluated by the in-cylinder pressure sensor (Figure 19b).

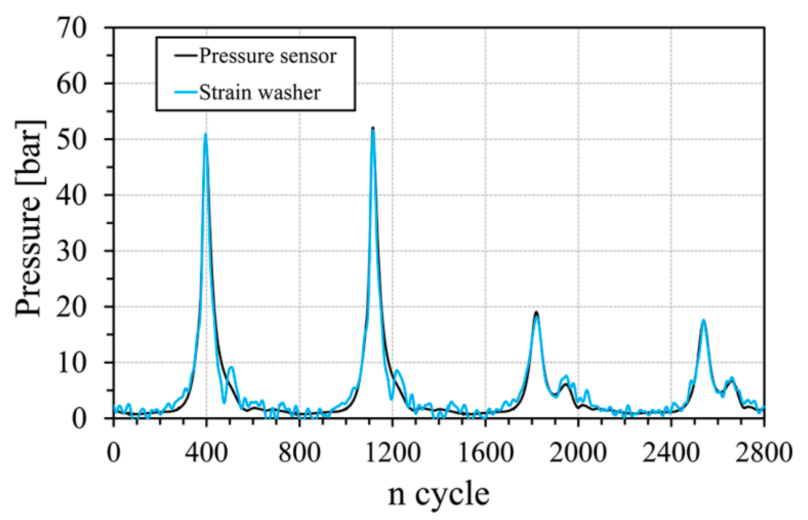

Figure 18. In-cylinder pressure of four consecutive cycles with misfiring events at $4000 \mathrm{rpm}$ and full load measured by the pressure sensor and derived from the strain washer signal.
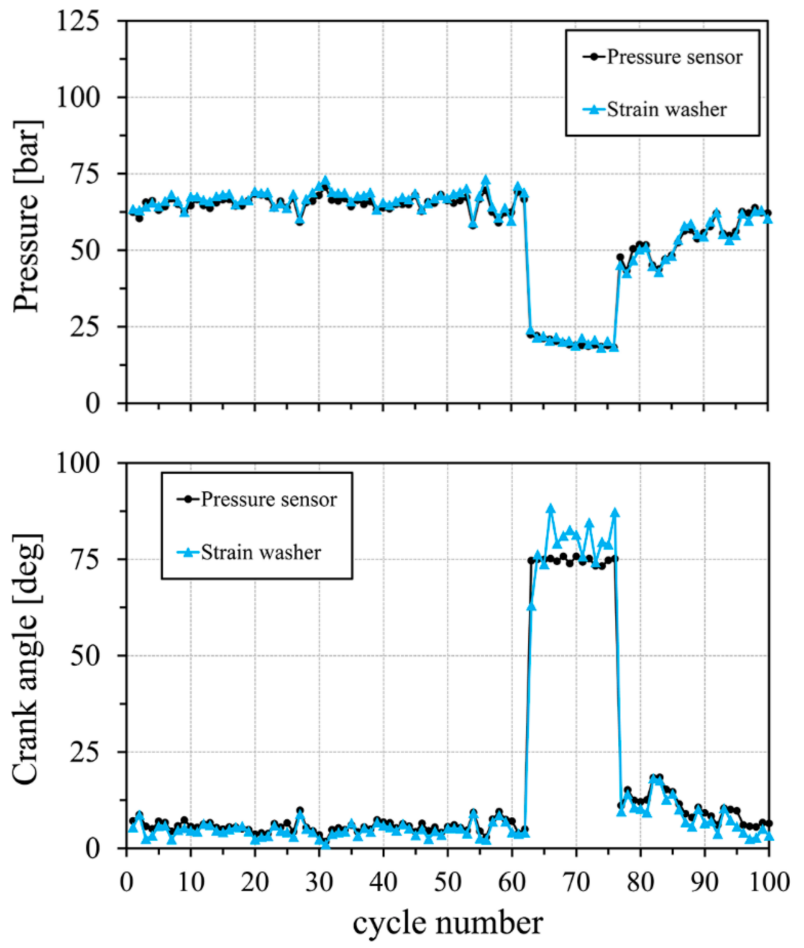

Figure 19. (a) Maximum in-cylinder pressure and (b) MBF50 evaluated by the strain washer and the pressure sensor in case of misfiring at $5000 \mathrm{rpm}$ and full load on 100 consecutive cycles.

\subsection{Knocking}

Knocking in spark ignition engines occurs when the combustion of the air/fuel mixture in the cylinder does not start correctly in response to the ignition by the spark plug, but one or more pockets of mixture explode outside the envelope of the normal combustion front. This phenomenon can be self-sustaining and produce some structural damages or failures of the engine due to the effect of the intense pressure peaks moving at high frequency inside the combustion chamber. In order to detect properly knocking phenomena, a cycle-to-cycle analysis is needed, since its traces can disappear in the average cycle. To evaluate the effectiveness of the proposed method in analyzing the knocking, detailed comparative analyses of different engine cycles were carried out. For example, Figure 20a 
shows two consecutive cycles among those sampled at $5000 \mathrm{rpm}$, which were characterized by the absence and the presence of knock, respectively. The signals were acquired with both the pressure sensor and the strain washer. Upon examination of the figure, it is apparent that the cycle affected by knock reached a much more intense pressure peak, followed by the arising of high-frequency oscillations of the in-cylinder pressure (for this reason, the whole frequency content of the SW signal needs to be considered for this analysis). This behavior is peculiar of the knocking phenomena, which are usually characterized by a high-frequency content above $6 \mathrm{kHz}$, even though this aspect also depends on the dimensions of the combustion chamber, and particularly on the bore [37,38]. Overall, the reconstruction of the cycle based on the SW was able to reproduce properly the effects of knocking, with an accurate description of both the pressure peak and its position. This is even more clearly visible in Figure 20b, which reports the zoomed view of the combustion phase in case of knock; again, the correct description of the frequency and amplitude of the fluctuations is apparent.
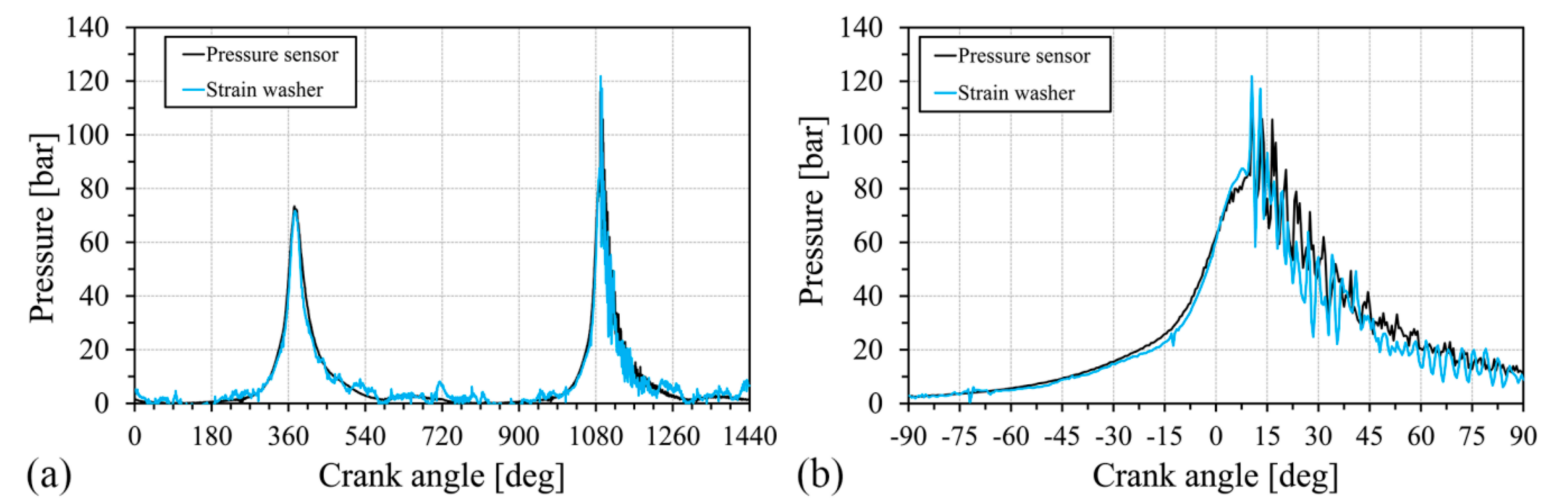

Figure 20. (a) In-cylinder pressure of two consecutive cycles with knock event at $5000 \mathrm{rpm}$ and full load measured by the pressure sensor and derived from the strain washer signal; (b) zoomed view of the combustion phase during the knocking event.

To get a further insight on the capability of the SW to describe properly the whole set of frequencies arising during knocking, the signals of Figure 20a were processed via a Fast-Fourier analysis in Figures 21 and 22, respectively. Upon examination of the FFT spectrum, it is apparent that almost the whole set of contributions within the high frequency can be observed almost in the same way analyzing both the pressure sensor and the strain washer signals, confirming the suitability of the strain washer for the knock detection.

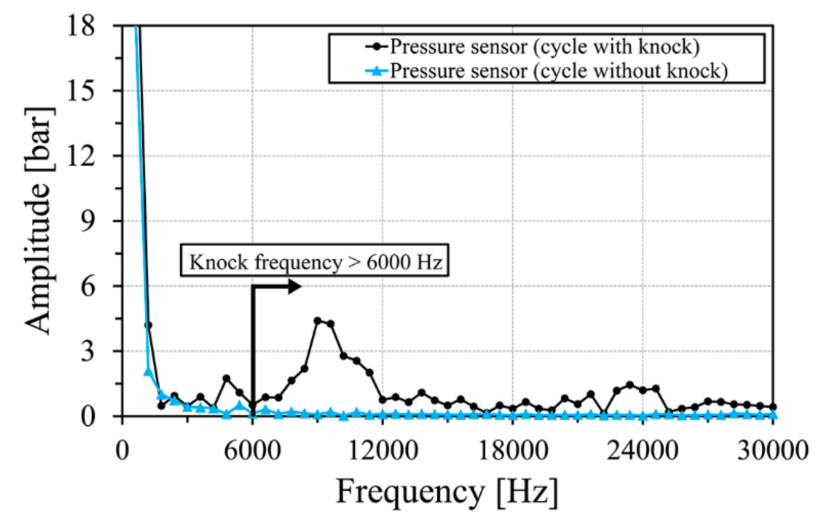

Figure 21. FFT spectrum of the pressure sensor signal between -10 CA deg and +45 CA deg in case of knock and without knock at 5000 rpm and full load. 


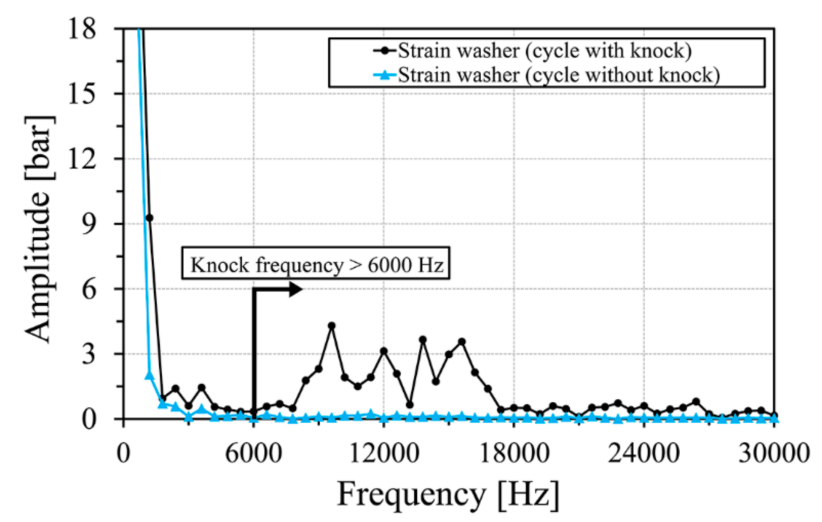

Figure 22. FFT spectrum of the in-cylinder pressure between -10 CA deg and +45 CA deg derived by the strain washer in case of knock and without knock at $5000 \mathrm{rpm}$ and full load.

\section{Conclusions}

An innovative experimental methodology for the indirect in-cylinder pressure measurement based on the use of a strain washer is proposed and fully documented in the study. The proposed solution presents some relevant advantages, i.e., (a) a simple sensor installation; (b) a direct correlation with the pressure inside the cylinder; (c) no limits related to engine operating conditions; (d) a simple data post-processing procedure. Future real-time engine control systems for the management of the combustion process would benefit from such a device (once ready for industry applications) since it would overcome the major issues related to the actual in-cylinder pressure sensors (such as cost and reliability).

The approach has been validated by means of an extended experimental data set collected at the test bench. Tests were performed on a $4 \mathrm{~S}$, single-cylinder, turbocharged, spark ignition engine. The strain washer was placed under one of the four studs of the engine head. The main outcomes of the analysis were:

- the existence of a linear correlation between the strain washer signal and the in-cylinder pressure was proved. The two tuning variables in the correlation were shown to be easily definable choosing reference points in proximity of the pressure peak. These results do represent the key potential of the present method, ensuring high robustness and applicability.

- the suitability of the use of the strain washer data to monitor the engine behavior was proved also in anomalous engine working conditions like misfiring, pre-ignition and knocking.

- in the case of single-cylinder, the accuracy in the prediction of IMEP was further improved by means of an additional correction of the method making use of a numerical 0D model in order to simulate the scavenging phase of the engine that falls in the uncertainty range of the sensor selected for the present activity.

Overall, the present study is the proof of concept of an approach that is thought to have a great potential for application in engine mass production thanks to its simplicity and accuracy. Future developments will include additional experimental tests aimed at verifying the reliability of the calibrated linear correlation with another engine of the same family. Moreover, the use of a strain washer in a multiple-cylinder engine will be carried out in order to assess the sensitivity of the sensor to the other cylinder stresses and to understand if a single strain washer is enough for the detection of the pressure cycle of all the cylinders or if more than one sensor is needed. In this case, a specific investigation on the influence of multiple combustions on the reconstruction of the pressure signal will be mandatory. It is expected that, by installing the SW between two cylinders, traces of both combustion processes will be seen by the sensor, probably making a specific correlation for each cylinder mandatory. Moreover, it is indeed likely that the SW signal correlated to one cylinder could be shifted, or generally modified, by the combustions process of other ones. 
Author Contributions: Conceptualization, L.R., G.F. and G.V.; Methodology, L.R., A.Bi. and G.V.; Software, L.R. and G.V.; Validation, L.R. and G.V.; Formal Analysis, A.B.; Investigation, L.R. and G.V.; Resources, G.F.; Data Curation, A.Bi.; Writing-Original Draft Preparation, L.R. and G.V.; Writing-Review \& Editing, A.Bi.; Visualization, A.Bi.; Supervision, G.F. and A.Be.; Project Administration, G.F.; Funding Acquisition, G.F. and A.Be.

Conflicts of Interest: The authors declare no conflict of interest.

\section{Nomenclature}

\begin{tabular}{|c|c|c|}
\hline $4 \mathrm{~S}$ & Four Stroke & - \\
\hline OD & 0 Dimensional & - \\
\hline AFR & Air Fuel Ratio & - \\
\hline ARMA & Autoregressive Moving Average & - \\
\hline ATDC & After Top Dead Center & - \\
\hline BDC & Before Dead Center & - \\
\hline BTDC & Before Top Dead Center & - \\
\hline CA & Crank Angle & - \\
\hline Dr & Dynamic Range & {$[\mathrm{N}]$} \\
\hline EGR & Exhaust Gas Recirculation & - \\
\hline EVC & Exhaust Valve Closing & - \\
\hline EVO & Exhaust Valve Opening & - \\
\hline FFT & Fast Fourier Transform & - \\
\hline FRF & Frequency Response Function. & - \\
\hline FTDC & Firing Top Dead Center & - \\
\hline IA & Ignition Advance & - \\
\hline IMEP & Indicated Mean Effective Pressure & - \\
\hline IVO & Intake Valve Opening & - \\
\hline MBF50 & $50 \%$ Mass Burned Fuel & - \\
\hline $\mathrm{Mr}$ & Measuring Range & {$[\mathrm{N}]$} \\
\hline $\mathrm{NN}$ & Neural Network & - \\
\hline RPM & Revolutions Per Minute & - \\
\hline SI & Spark Ignition & - \\
\hline PS & Pressure Sensor & - \\
\hline PFI & Port fuel Injection & - \\
\hline SW & Strain Washer & - \\
\hline
\end{tabular}

\section{Variables}

\begin{tabular}{lll}
\hline$k$ & Slope & {$[\mathrm{N} / \mathrm{bar}]$} \\
$q$ & y-intercept & {$[\mathrm{bar}]$} \\
$\gamma$ & Ratio of specific heat & - \\
$V$ & Volume & {$\left[\mathrm{m}^{3}\right]$} \\
$p$ & Pressure & {$[\mathrm{bar}]$} \\
$\theta$ & Crankshaft angular position & {$[\mathrm{deg}]$} \\
$Q_{b}$ & Released heat & {$[\mathrm{kJ}]$} \\
\hline
\end{tabular}

\section{Subscripts}

\begin{tabular}{lll}
\hline $\mathrm{i}$ & Initial & - \\
$\mathrm{f}$ & Final & - \\
\hline
\end{tabular}




\section{References}

1. Puškár, M.; Kopas, M. System based on thermal control of the HCCI technology developed for reduction of the vehicle NOX emissions in order to fulfil the future standard Euro 7. Sci. Total Environ. 2018, 643, 674-680. [CrossRef] [PubMed]

2. Carlucci, A.P.; Laforgia, D.; Motz, S.; Saracino, R.; Wenzel, S.P. Advanced closed loop combustion control of a LTC diesel engine based on in-cylinder pressure signals. Energy Convers. Manag. 2014, 77, $193-207$. [CrossRef]

3. Pestana, G. Engine Control Methods Using Combustion Pressure Feedback; SAE Technical Paper 890758; SAE: Warrendale, PA, US, 1989. [CrossRef]

4. Wibberley, P.; Clark, C. An Investigation of Cylinder Pressure as Feedback for Control of Internal Combustion Engines; SAE Technical Paper 890396; SAE: Warrendale, PA, USA, 1989. [CrossRef]

5. Giglio, V.; Iorio, B.; Police, G.; Rispoli, N. In-Cylinder Pressure Measurement for Control and Diagnostics in Spark Ignition Engines; SAE Technical Paper 2005-24-062; SAE: Warrendale, PA, USA, 2005. [CrossRef]

6. Carlucci, A.; Benegiamo, M.; Camporeale, S.; Ingrosso, D. Improvement of the Control-Oriented Model for the Engine-Out NOX Estimation Based on In-Cylinder Pressure Measurement; SAE Technical Paper 2017-24-0130; SAE: Warrendale, PA, USA, 2017. [CrossRef]

7. Olsson, J.; Tunestål, P.; Johansson, B. Closed-Loop Control of an HCCI Engine; SAE Technical Paper 2001-01-1031; SAE: Warrendale, PA, USA, 2001. [CrossRef]

8. Kang, J.; Chang, C.; Chen, J.; Chang, M. Concept and Implementation of a Robust HCCI Engine Controller; SAE Technical Paper 2009-01-1131; SAE: Warrendale, PA, USA, 2009. [CrossRef]

9. Aulin, H.; Bentioulis, P.; Tunestål, P.; Hyvönen, J.; Johansson, B. Improving Ion Current Feedback for HCCI Engine Control; SAE Technical Paper 2007-01-4053; SAE: Warrendale, PA, USA, 2007. [CrossRef]

10. Herden, W.; Küsell, M. A New Combustion Pressure Sensor for Advanced Engine Management; SAE Technical Paper 940379; SAE: Warrendale, PA, USA, 1994. [CrossRef]

11. Mobley, C. Non-Intrusive In-Cylinder Pressure Measurement of Internal Combustion Engines; SAE Technical Paper 1999-01-0544; SAE: Warrendale, PA, USA, 1999. [CrossRef]

12. Zhang, H.; Du, L.; Shi, X. Reconstructing cylinder pressure from vibration signals based on radial basis function networks. Proc. Inst. Mech. Eng. D-J. Automob. Eng. 2001. [CrossRef]

13. Gao, Y.; Randall, R.B. Reconstruction of diesel engine cylinder pressure using a time domain smoothing technique. Mech. Syst. Signal Process. 1999, 13, 709-722. [CrossRef]

14. Sellnau, M.; Matekunas, F.; Battiston, P.; Chang, C.; Lancaster, D.R. Cylinder-Pressure-Based Engine Control Using Pressure-Ratio-Management and Low-Cost Non-Intrusive Cylinder Pressure Sensors; SAE Technical Paper 2000-01-0932; SAE: Warrendale, PA, USA, 2000. [CrossRef]

15. Ausserer, J.; Rowton, A.; Grinstead, K.; Litke, P.; Polanka, M.D. Comparison of In-Cylinder Pressure Measurement Methods in a Small Spark Ignition Engine; SAE Technical Paper 2014-32-0007; SAE: Warrendale, PA, USA, 2014. [CrossRef]

16. Roth, K.; Sobiesiak, A.; Robertson, L.; Yates, S. In-Cylinder Pressure Measurements with Optical Fiber and Piezoelectric Pressure Transducers; SAE Technical Paper 2002-01-0745; SAE: Warrendale, PA, USA, 2002. [CrossRef]

17. Anderson, R. In-Cylinder Measurement of Combustion Characteristics Using Ionization Sensors; SAE Technical Paper 860485; SAE: Warrendale, PA, USA, 1986. [CrossRef]

18. Jia, L.; Naber, J.; Blough, J.; Alireza Zekavat, S. Accelerometer-Based Combustion Metrics Reconstruction with Radial Basis Function Neural Network for a 9 L Diesel Engine. J. Eng. Gas Turb. Power-Trans. ASME 2014, 13. [CrossRef]

19. Moro, D.; Cavina, N.; Ponti, P. In-cylinder Pressure Reconstruction Based on Instantaneous Engine Speed Signal. J. Eng. Gas Turbines Power 2001, 124, 220-225. [CrossRef]

20. El-Ghamry, M.; Steel, J.; Reuben, R. Indirect measurement of cylinder pressure from diesel engines using acoustic emission. Mech. Syst. Signal Process. 2005, 19, 751-765. [CrossRef]

21. Antoni, J.; Randall, R.; Guillet, F. Indirect Reconstruction of ICE pressure trace through structural vibration inverse filtering. In Proceedings of the International Congress and Exhibition on Noise Control Engineering, Nice, France, 27-30 August 2000.

22. Fleming, W.J. New automotive sensors-A review. IEEE Sens. J. 2008, 8, 1900-1921. [CrossRef] 
23. Moskwa, J.; Bucheger, D. A new methodology for use in engine diagnostics and control, utilizing "synthetic" engine variables: Theoretical and experimental results. J. Dyn. Syst. 2001, 123, 528-534. [CrossRef]

24. Bengtsson, F. Estimation of Indicated-And Load-Torque from Engine Speed Variations. Master's Thesis, Linkoping University, Linköping, Sweden, 21 June 2006.

25. Vignocchi, D. Elementi di Progettazione del Motore; Athena srl: Modena, Italy, 2002.

26. Hamedovic, H.; Raichle, F.; Breuninger, J.; Fischer, W.; Dieterle, W.; Klenk, M. IMEP-Estimation and In-Cylinder Pressure Reconstruction for Multicylinder SI-Engine by Combined Processing of Engine Speed and One Cylinder Pressure. In Proceedings of the SAE World Congress \& Exhibition, Detroit, MI, USA, 21-23 April 2015.

27. Frelund, A.R. Engine Combustion Chamber Pressure Sensor. U.S. Patent 4,601,196, 22 July 1986.

28. Sellnau, M. Combustion Pressure Sensor. U.S. Patent 4,969,352, 13 November 1990.

29. Sellnau, M. Non-Intrusive Cylinder Pressure Sensor Having Improved Response Characteristics. U.S. Patent 5,367,904, 29 November 1994.

30. Sawamoto, K. Combustion Pressure Sensor Arrangement. U.S. Patent 4,602,506, 29 July 1986.

31. Romani, L.; Lenzi, G.; Ferrari, L.; Ferrara, G. Indirect Estimation of In-Cylinder Pressure through the Stress Analysis of an Engine Stud; SAE Technical Paper 2016-01-0814; SAE: Warrendale, PA, USA, 2016. [CrossRef]

32. Romani, L.; Vichi, G.; Ferrara, G.; Balduzzi, F.; Trassi, P.; Fiaschi, J.; Tozzi, F. Development of a Low Pressure Direct Injection System for a Small 2S Engine. Part II-Experimental Analysis of the Engine Performance and Pollutant Emissions; SAE Technical Paper 2015-01-1730; SAE: Warrendale, PA, USA, 2015. [CrossRef]

33. Heywood, J.B. The Two-Stroke Cycle Engine; SAE International: Warrendale, PA, USA, 1989.

34. Romani, L.; Vichi, G.; Bianchini, A.; Ferrari, L.; Ferrara, G. Optimization of the Performance of a Formula SAE Engine by means of a Wastegate Valve Electronically Actuated. Energy Procedia 2016, 101, 654-661. [CrossRef]

35. Heywood, J.B. Internal Combustion Engine Foundamentals; McGraw-Hill: New York, NY, USA, 1988.

36. Hadelmovic, H. IMEP-Estimation and In-Cylinder Pressure Reconstruction; SAE International: Warrendale, PA, USA, 2005.

37. Horner, T. Knock Detection Using Spectral Analysis Techniques on a Texas Instruments TMS320 DSP; SAE Technical Paper 960614; SAE: Warrendale, PA, USA, 1996. [CrossRef]

38. Wang, Z.; Liu, H.; Rolf, D.R. Knocking combustion in spark-ignition engines. Prog. Energy Combust. Sci. 2017, 61, 78-112. [CrossRef] 